\title{
ASSOCIAÇÃO ENTRE INIMIGOS NATURAIS E Spodoptera frugiperda (J.E. SMITH, 1797) (LEPIDOPTERA: NOCTUIDAE) NA CULTURA DO MILHO
}

\author{
MARIA DE LOURDES CORRÊA FIGUEIREDO ${ }^{1}$, ANGÉLICA MARIA PENTEADO MARTINS-DIAS ${ }^{2}$ \\ e IVAN CRUZ ${ }^{3}$
}

${ }^{1}$ Pesquisadora (bolsista PD/CNPq) Embrapa Milho e Sorgo, Caixa Postal 151, CEP 35701-970, Sete Lagoas, MG. Email lude@cnpms.embrapa.br (autor para correspondência)

${ }^{2}$ Professora, Departamento de Biologia Evolutiva, Universidade Federal de São Carlos, Caixa Postal 676, CEP: 13565905 São Carlos, SP. angelica@power.ufscar.br

${ }^{3}$ Pesquisador, Embrapa Milho e Sorgo, Caixa Postal 151, CEP: 35700-970, Sete Lagoas, MG. ivancruz@cnpms.embrapa.br

Revista Brasileira de Milho e Sorgo, v.5, n.3, p.340-350, 2006

RESUMO - O experimento foi realizado na safra de verão, em área de cerrado, em Sete Lagoas, MG. Foi avaliada a ocorrência de inimigos naturais associados à Spodoptera frugiperda, na cultura do milho (Híbrido BRS 3123), partindo-se de uma única infestação artificial com uma postura da praga a cada cinco plantas, através de amostragens (20 plantas por parcela) realizadas a cada dois dias, sendo a primeira realizada dois dias após a infestação e a última, 16 dias após a infestação. As lagartas coletadas foram colocadas individualmente em copos de plástico contendo dieta artificial até a emergência dos parasitóides ou do adulto da praga. Foram observados os predadores de ovos e lagartas Orius sp. (Heteroptera: Anthocoridae) e Doru luteipes Scudder (Dermaptera: Forficulidae). Entre os parasitóides, Chelonus insularis (Cresson) (Hymenoptera: Braconidae), presente em todas as coletas, respondeu por $91 \%$ do parasitismo. Também da ordem Hymenoptera, foram identificados Eiphosoma laphygmae Costa Lima (Ichneumonidae), Exasticolus fuscicornis (Cameron) (Braconidae), Cotesia marginiventris (Cresson) (Braconidae), Campoletis flavicincta (Ashmead) (Ichneumonidae) e Pristomerus spinator (Fabricius) (Ichneumonidae). Archytas incertus (Macquart) (Diptera: Tachinidae) também foi coletado na área experimental.

Palavras-chave: Controle biológico, predadores, parasitóides, lagarta-do-cartucho

\section{RELATIONSHIP BETWEEN NATURAL ENEMIES AND Spodoptera frugiperda (J.E. SMITH, 1797) (LEPIDOPTERA: NOCTUIDAE) ON MAIZE CROP}

\begin{abstract}
The experiment was conducted during the summer season in a savanna type soil in Sete Lagoas, MG, Brazil. The occurrence of natural enemies associated to Spodoptera frugiperda (J.E. Smith, 1797) (Lepidoptera: Noctuidae) on maize crop (Hybrid BRS 3123) was evaluated from a single artificial infestation with one egg mass in each five plant set. Random samples ( 20 plants/plot) were collected at a two-day interval, the first one two days after infestation and the last 16 days. The host larvae were individually placed inside a plastic cup contained artificial diet until natural enemies emergence. The insect predators Orius sp. (Heteroptera: Anthocoridae) and Doru luteipes Scudder
\end{abstract}


(Dermaptera: Forficulidae) were the main especies found. Among parasitoids, Chelonus insularis (Cresson), (Hymenoptera: Braconidae) present in all samples, represented 91\% of the collected species. Other Hymenoptera species included Eiphosoma laphygmae Costa Lima (Ichneumonidae), Exasticolus fuscicornis (Cameron) (Braconidae), Cotesia marginiventris (Cresson) (Braconidae), Campoletis flavicincta (Ashmead) (Ichneumonidae), and Pristomerus spinator (Fabricius) (Ichneumonidae). Archytas incertus (Macquart) (Diptera: Tachinidae) was also collected inside the experimental area.

Key words: Biological control, insect predators, parasitoids, fall armyworm

Spodoptera frugiperda (J.E. Smith, 1797) (Lepidoptera: Noctuidae) é uma espécie polífaga, que se alimenta tanto de plantas nativas quanto cultivadas e tem no milho seu hospedeiro preferencial, podendo ocasionar perdas na produção que variam de 15 a 34\%, culminando em grandes prejuízos aos agricultores (Cruz \& Turpin, 1982; Cruz et al., 1996).

As condições tropicais anuais, em termos de clima, são favoráveis ao desenvolvimento da praga, que, encontrando abundância de alimento, consegue desenvolver várias gerações anuais (Cruz, 1995). Assim sendo, especialmente no Brasil, praticamente todas as fases de desenvolvimento do cultivo do milho são atacadas pela praga, exigindo, muitas vezes, a utilização de medidas de controle, geralmente com inseticidas químicos. Tais produtos, geralmente com amplo espectro de ação, por muitos anos desempenharam papel importante na proteção de vários cultivos de importância agrícola. No entanto, talvez pelo excesso de confiabilidade na eficiência daqueles inseticidas, sua aplicação foi banalizada e passou a ser rotina na agricultura, sem se preocupar muito com os possíveis efeitos danosos ao meio ambiente, incluindo intoxicações no homem, nos organismos não-alvos e até mesmo o aparecimento de pragas resistentes aos produtos utilizados. Entre os organismos não alvos, encon- tram-se agentes de controle natural, muitas vezes desconhecidos, tanto no que diz respeito à diversidade quanto à capacidade de suprimir os insetos nocivos. O conhecimento da comunidade de insetos presentes em um determinado ecossistema é de grande importância não só para avaliar o impacto ambiental, mas, principalmente, para definir estratégias de manejo de pragas (Santos \& Marques, 1996).

O desenvolvimento de populações de insetos com resistência a diferentes grupos de inseticidas químicos, a demanda da sociedade por alimentos saudáveis ou até por questões legislativas, como é o caso da agricultura orgânica, têm levado a busca de alternativas para o controle de pragas, como o controle biológico. Para se estabelecer um programa de manejo de pragas, considerando como componente fundamental à contribuição de agentes de controle natural, é necessário que se conheçam, em bases locais ou regionais, quais são as espécies importantes, mais freqüentes e as suas potencialidades para uso aplicado. A utilização correta de um agente de controle biológico natural pode trazer benefícios imediatos ao agronegócio, por agir diretamente sobre a praga, reduzindo sua densidade populacional no agroecossistema do milho, e ao ambiente, por propiciar uma redução na quantidade de agroquímicos aplicados. 
Relatos de inimigos naturais de $S$. frugiperda já foram publicados no Brasil, notadamente nos últimos anos (Lucchini \& Almeida, 1980, Reis et al., 1988, Valicente, 1989, Cruz, 1995, 2002, Rezende et al., 1995, Silva et al., 1997, Valicente \& Barreto, 1999, Cruz et al., 1997, 1999, Figueiredo et al., 1999, 2002) e no exterior Molina-Ochoa et al. (2001, 2004). Esses trabalhos apontam o potencial de uso do controle biológico para a supressão da praga, necessitando, para tornar-se realidade, a intensificação dos programas de pesquisa sobre o assunto. No entanto, poucos trabalhos têm sido direcionados ao longo do ciclo biológico da praga.

Este trabalho teve como objetivo avaliar a frequiência e a distribuição dos inimigos naturais de $S$. frugiperda, a partir de infestação artificial com posturas da praga na cultura de milho, visando associar a presença dos agentes de controle biológico aos diferentes estádios de desenvolvimento do inseto hospedeiro.

\section{Material e Métodos}

O experimento foi realizado na safra de verão, em Sete Lagoas, MG, cujas coordenadas são: latitude de $19^{\circ} 28^{\prime}$ 00'S e longitude de $44^{\circ}$ 15 "08" W. A temperatura média anual da região é de $22,1^{\circ} \mathrm{C}$ e a maior precipitação pluvial mensal ocorre em dezembro (305,9 mm). A umidade relativa apresenta valores mais elevados em dezembro (78\%), janeiro e fevereiro (77\%), com amplitude anual de $16 \%$, sendo a região considerada como semi-úmida. Os maiores valores de velocidade média dos ventos são encontrados no trimestre agosto, setembro e outubro $(2,1 \mathrm{~m} / \mathrm{s})$ e os menores, em abril, maio e junho (1,5 m/s).

Próximo à área experimental, existe uma mata nativa de cerrado, uma rua onde transitam veículos e equipamentos agrícolas e culturas de milho e sorgo destinadas a estudos de melhora- mento genético. Antes do plantio a área estava em pousio, sendo que a cultura anterior também havia sido o milho. Foi utilizado o híbrido triplo BRS 3123, em plantio direto, semeado na segunda quinzena de novembro, adubado com $400 \mathrm{~kg}$ /ha da fórmula 4-14-8. Foi também utilizada uma adubação de cobertura (uréia), aos 35 dias após a emergência das plantas. $\mathrm{O}$ espaçamento foi de um metro entre fileiras, ajustando uma densidade de cinco plantas por metro linear. A irrigação por aspersão foi realizada somente quando necessária.

O delineamento foi em blocos ao acaso, com oito tratamentos e cinco repetições, sendo cada parcela constituída por quatro fileiras de milho com três metros de comprimento $\left(12 \mathrm{~m}^{2}\right)$. Quinze dias após a emergência das plantas, foi realizada uma única infestação artificial.

Em todas as parcelas, foi distribuída uma postura, a cada cinco plantas $\left(1 \mathrm{~m}^{2}\right)$, contendo cerca de 100 ovos, com 24 horas de desenvolvimento embrionário. As posturas de $S$. frugiperda foram fixadas na parte inferior da folha do milho, de forma semelhante àquela observada naturalmente, quando depositadas pela praga. No mesmo dia da infestação, foi medida a altura de 20 plantas ao acaso e determinado o estádio de desenvolvimento da cultura (Guimarães \& Durães, 2002). A altura média das plantas, no dia da infestação, era de $20,73 \mathrm{~cm}$, as quais estavam entre o estágio fenológico V3 e V4.

Os tratamentos foram definidos de acordo com a época da coleta das plantas de milho, sendo realizada a cada dois dias a partir da infestação, terminando com a coleta das plantas aos 16 dias após a infestação.

A cada coleta, 20 plantas de cada parcela foram aleatoriamente cobertas com uma sacola de plástico e depois cortadas pela base, permitindo, assim, a coleta de todos os insetos presen- 
tes nas folhas. As plantas foram coletadas pela manhã, a partir das oito horas e, logo em seguida, levadas para o laboratório. Cada planta teve suas folhas destacadas e avaliadas quanto à presença de insetos. As posturas e lagartas de $S$. frugiperda foram colocadas em copos de $50 \mathrm{ml}$, contendo dieta artificial; os demais insetos presentes nas plantas foram colocados em solução de álcool $70 \%$.

Os inimigos naturais, provenientes dos diferentes estádios de desenvolvimento da praga, foram separados e agrupados de acordo com sua classificação entomológica.

As posturas provenientes de infestação natural da praga foram verificadas somente nas plantas coletadas e avaliadas separadamente, de forma semelhante àquelas provenientes da infestação artificial.

Os insetos da ordem Hymenoptera foram identificados pela Dra. Angélica Maria Penteado Martins-Dias (Departamento de Biologia Evolutiva da Universidade Federal de São Carlos) e da ordem Diptera, pelo Dr. Ronaldo Toma (Museu de Zoologia da Universidade de São Paulo, USP).

Os dados foram submetidos às análises de regressão e de variância, sendo as médias comparadas pelo teste de Duncan, a 5\% de probabilidade.

\section{Resultados e Discussão}

Foram totalizadas 2.198 lagartas nas plantas durante as coletas e, dessas 1.153 estavam parasitadas, ou seja, uma taxa média de 52,45\% de parasitismo (Tabela 1). Silva et al. (1997), em coletas realizadas nos anos agrícolas de 1991/92 e 1992/93, em várias localidades de Minas Gerais, encontraram uma taxa média de 19,3\% de parasitismo (em 1.106 lagartas coletadas). Na área experimental, a taxa de parasitismo foi mais alta

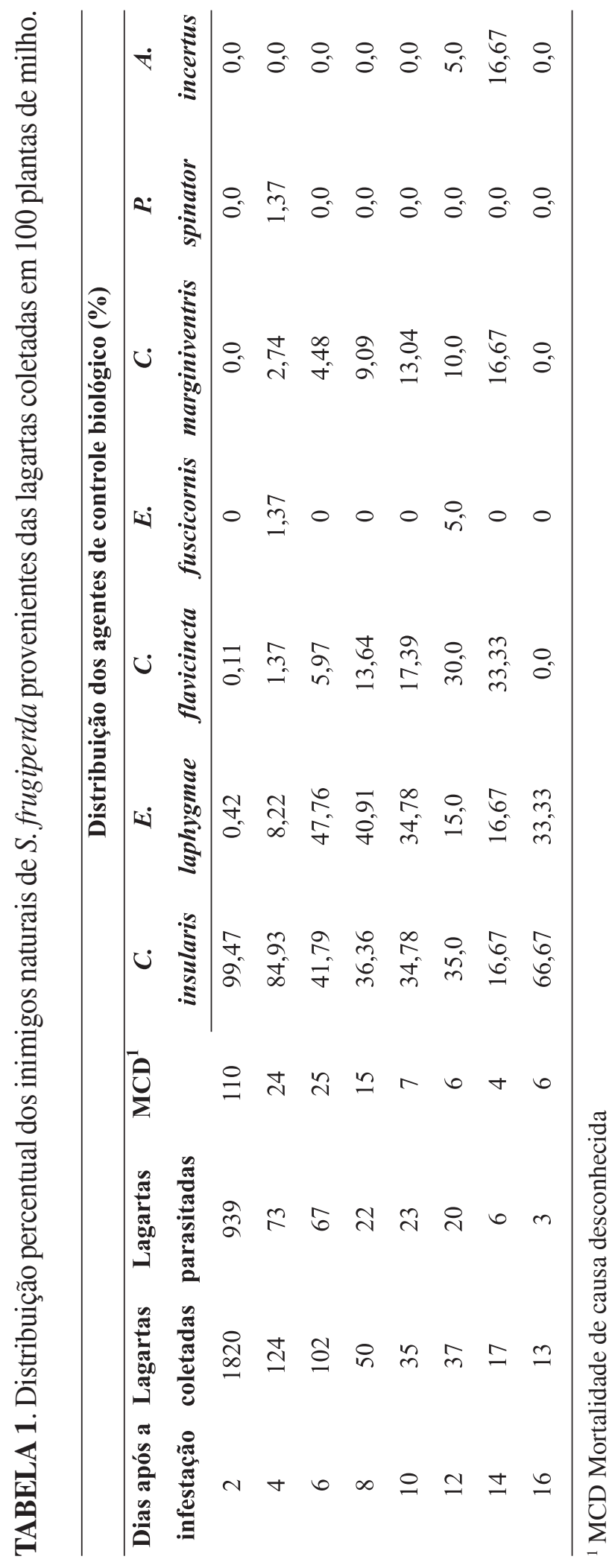


e esse fato pode estar relacionado ao índice de infestação, que, nesse caso, foi artificial, e também porque, nessa área, não se usa inseticida, enquanto que no trabalho citado foi avaliada a ocorrência do parasitismo em infestação natural. Além desse fato, diversos fatores bióticos e ou abióticos afetam diretamente a ocorrência da praga, como também a de seus inimigos naturais. Nesse caso, pode ser observado um efeito significativo dos agentes de controle natural na área infestada artificialmente. A média de lagartas coletadas, que foi de 364 na primeira amostragem, reduziu-se para 2,6 na última, média significativamente diferente (Tabela 2 ).

Lagartas pequenas e de tamanho médio foram observadas em uma mesma planta nas primeiras amostragens. Nas amostragens seguintes, em geral, o número de lagartas por planta decresceu com o aumento do seu tamanho. A queda significativa na população de lagartas a cada coleta pode ser atribuída a fatores intrínsecos da espécie, como o canibalismo, a dispersão, a mortalidade natural e a ação dos agentes de controle biológico, os quais podem influenciar a sua distribuição na cultura do milho (Mitchell \& Fuxa, 1987; Muruá et al., 2006).

A análise de regressão indicou uma redução significativa de lagartas a partir de quatro dias após a infestação (Figura 1). Segundo Beserra et al. (2002), a distribuição de lagartas e ovos de S. frugiperda, varia de acordo com o estágio fenológico da planta de milho e que, durante os estágios (V1-V3) de desenvolvimento da planta, o primeiro e o segundo instares da praga foram predominantes, ocorrendo de uma a seis lagartas por planta e, em V4 e V6, geralmente foi observada somente uma lagarta por planta.

Na primeira amostragem, ou seja, na coleta de plantas dois dias após a infestação (2 DAI), o número médio de lagartas parasitadas foi o

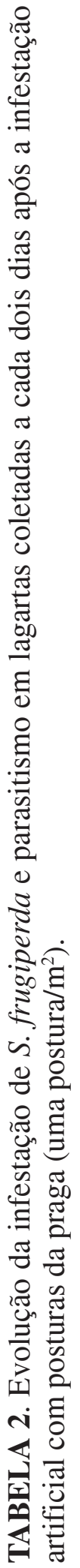




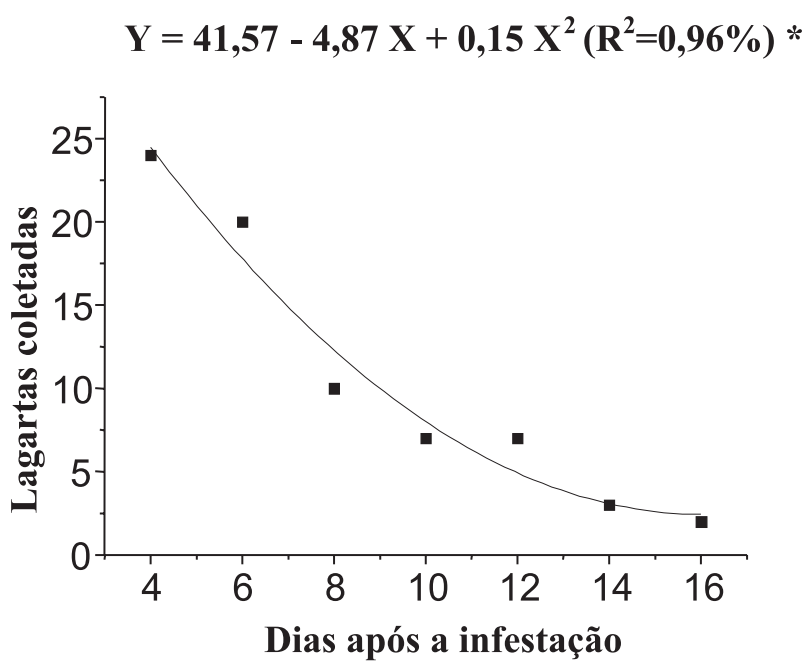

FIGURA 1. Relação do número de lagartas encontradas nas plantas de milho em função dos diferentes períodos de coleta.

(* Significativo a $5 \%$ ).

maior $(187,8)$ e diferiu significativamente das demais médias, cujos valores variaram entre 0,6 (última coleta-16 DAI) e 14,4 (segunda coleta 4 DAI) (Tabela 2).

Observa-se que nem sempre o maior número de lagartas parasitadas correspondeu à maior percentagem de parasitismo nas diferentes coletas. O maior valor observado foi de $67,43 \%$ de parasitismo aos $10 \mathrm{DAI}$, seguido das coletas aos 6, 4, 2, 12, 8 e 14 DAI, cuja percentagem média foi de 63,9, 56,4, 52,7, 52,1, 45,6 e 28,0\%, respectivamente, e não diferiram entre si (Tabela 2). A percentagem média de lagartas parasitadas na última coleta (16 DAI) foi de apenas 12,0\%, cuja média não diferiu daquela observada aos $8 \mathrm{e}$ 14 DAI, porém, significativamente diferente das demais coletas (Tabela 2). No entanto, o número de lagartas coletadas foi muito baixo.

Ajustando os dados através da análise de regressão, entre época de amostragem (DAI) e lagartas parasitadas, obteve-se o melhor ajuste com a função quadrática (Figura 2). O coeficien-

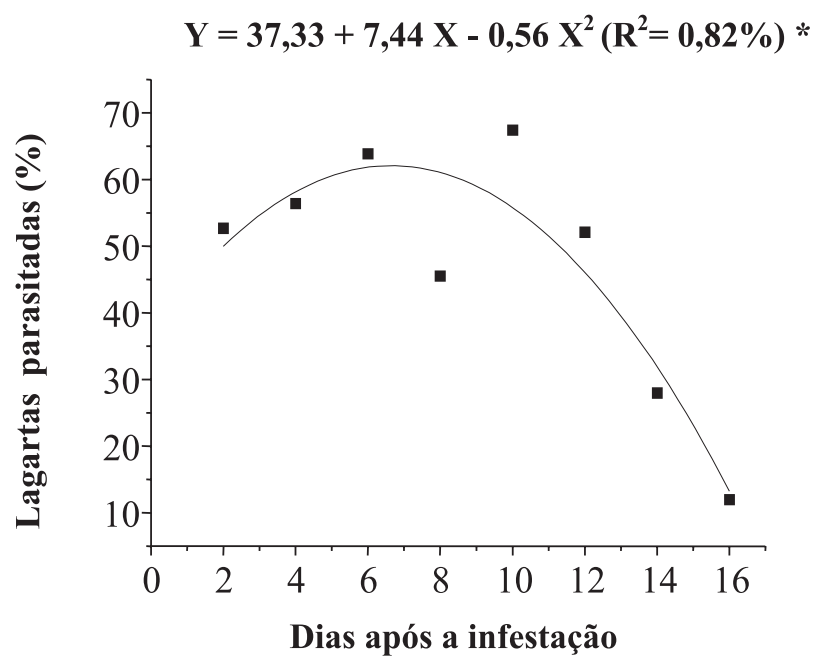

FIGURA 2. Percentagem de lagartas parasitadas em função dos diferentes períodos de coleta.

(* Significativo a $5 \%$ ).

te de determinação obtido foi significativo $\left(\mathrm{R}^{2}=0,82\right)$. Esse resultado demonstra claramente que, estando presentes na área, os inimigos naturais podem efetivamente manter a população de $S$. frugiperda sob controle. Mesmo tendo uma alta densidade de lagartas no início da infestação, a tendência é que tais lagartas sejam eliminadas por fatores naturais e ou pelos seus inimigos naturais, antes que causem danos significativos à planta.

Entre os parasitóides obtidos das lagartas parasitadas, houve predominância de espécies da ordem Hymenoptera. Foi constatada a ocorrência do parasitóide de ovo/lagarta Chelonus insularis Cresson (Braconidae) e dos parasitóides de lagartas Eiphosoma laphygmae Costa Lima (Ichneumonidae), Campoletis flavicincta (Ashmead) (Ichneumonidae), Cotesia marginiventris (Cresson) (Braconidae), Pristomerus spinator (Fabricius) (Ichneumonidae) e Exasticolus fuscicornis (Cameron) (Braconidae). Archytas incertus (Macquart) (Diptera: 
Tachinidae) foi o único representante dessa ordem.

A ocorrência de várias espécies de inimigos naturais e a incidência dos parasitóides sobre os diferentes instares da praga demonstraram que há um certo sincronismo na atuação de cada um, principalmente, quando não há uma interferência direta no agroecossistema, como o uso de inseticidas. Maior diversidade de espécies e maior proporção de parasitismo foram observadas em culturas de milho próximas a habitat de maior diversidade ecológica, como florestas, bosques, hortas, citricultura, pastagens, segundo Molina-Ochoa et al. (2001), cujas evidências apresentaram o diferencial de distribuição para alguns parasitóides nativos, servindo como um indicativo de sua escassez ou abundância em uma área definida geograficamente.

O parasitóide $C$. insularis foi observado em todas as épocas de coleta, com taxas de parasitismo variando de 16,7 a 99,5\%, nas coletas realizadas aos 14 e aos dois dias após a infestação, respectivamente (Tabela 1). Essa espécie tem sido mencionada como a de maior distribuição e com maiores índices de parasitismo dentre os demais parasitóides de $S$. frugiperda, na América do Norte. Molina-Ochoa et al. (2004) observaram de um total de 5591 lagartas coletadas no México, que 772 originaram parasitóides, para uma taxa de parasitismo de $13,8 \%$, sendo que a espécie amplamente distribuída foi de $C$. insularis, representado em 45,3\% das localidades inventariadas, seguido por $P$. spinator, que apresentou alta taxa de parasitismo, com 22,2\%.

As espécies do gênero Chelonus, como C. insularis, embora colocando seus ovos nos ovos do hospedeiro, permitem a eclosão das lagartas. No entanto, após a eclosão, a lagarta parasitada tem um desenvolvimento diferenciado daquelas não parasitadas, diminuindo sensi- velmente a quantidade de alimento ingerido, não causando danos econômicos (Rezende et al., 1995). A maior ocorrência de $C$. insularis foi verificada na coleta realizada aos dois dias após a infestação, ocasião também em que se coletou o maior número de lagartas de $S$. frugiperda. Não se pode descartar a possibilidade de que uma lagarta parasitada por esse agente de controle biológico se torne mais sensível ainda a outros fatores externos, especialmente predadores, como também, não se deve descartar uma possível interação com outros parasitóides de lagartas e ao próprio canibalismo. Esse fato pode, inclusive, explicar a redução no número de lagartas durante as coletas, cujos valores foram de 1.820 e 13 lagartas, para a primeira e última coletas, respectivamente (Tabela 1 e Figura 1). Não foram coletadas espécies de parasitóides específicos de ovos.

Verificou-se que o parasitóide de lagartas E. laphygmae foi o segundo em termos de maior ocorrência e freqüência, com uma variação de $0,42 \%$ (2 DAI) a 47,76\% (6 DAI) e média de $24,6 \%$ das lagartas parasitadas (Tabela 1). $C$. flavicincta não ocorreu na última coleta (16 DAI) e sua média de parasitismo foi de $1,82 \%$, com variação de 0,11 a 33,33\% de lagartas parasitadas. Essa espécie também foi observada no México, por Molina-Ochoa et al. (2001), em lagartas de S. frugiperda, com, $23 \%$ de parasitismo.

E. fuscicornis foi observado somente nas coletas realizadas aos 4 e 12 DAI, com 1,37 e $5,0 \%$ de parasitismo, respectivamente, e média de $0,17 \%$ (Tabela 1 ).

O parasitóide $C$. marginiventris esteve presente a partir de 4 DAI $(2,74 \%)$, até a coleta aos 14 DAI $(16,67 \%)$ e o parasitóide $P$. spinator foi observado somente na coleta aos 4 DAI, com $1,37 \%$. A. incertus (Diptera) foi observado somente a partir da coleta aos 12 DAI $(5,0 \%)$ e ter- 
minando aos 14 DAI (16,67\%), com uma média de parasitismo igual a $0,17 \%$ (Tabela 1 ).

A partir dos 12 DAI é que foi verificada a ocorrência de Diptera nas coletas. Das 1.050 lagartas parasitadas, 97,29\% foram por Hymenoptera e somente duas lagartas foram parasitadas por Diptera (2,71\%) (Tabela 2). Dos parasitóides coletados em Vipos, Argentina, Murúa et al. (2006) observaram que 38,3\% do parasitismo em lagartas de $S$. frugiperda foi ocasionado por Archytas spp. No Brasil, Silva et al. (1997) verificaram uma associação significativa entre parasitóides Hymenoptera e Diptera, os quais não competem pela mesma fase de desenvolvimento do hospedeiro. Molinari \& Avalos, (1997), enfatizaram que espécies da família Tachinidae geralmente parasitam os últimos instares de lagartas de $S$. frugiperda, comuns em plantas de milho a partir de V4.

Na América do Sul, Archytas marmoratus (Townsend) e A. incertus foram destacados pelo importante papel na supressão dessa praga, por Molina-Ochoa et al. (2004) e, especificamente na Argentina, Murúa et al. (2006) observaram que, das lagartas coletadas, $2,1 \%$, e $10,5 \%$ estavam parasitadas pelas respectivas espécies.

Durante as coletas foram observadas, nas parcelas experimentais, apenas sete posturas de campo (infestação natural). Destas, eclodiram 408 lagartas, uma média de 58,29 lagartas/postura, sendo que 69 lagartas estavam parasitadas por C. insularis, o que corresponde a $16,91 \%$. A maior ocorrência desse parasitóide pode estar associada também ao fato de que, ao parasitar os ovos da praga, sua larva já está mais desenvolvida e, portanto, em melhor condição para se defender e eliminar os demais parasitóides que possam ter sido depositados na mesma lagarta de $S$. frugiperda, posteriormente. A predominância de C. insularis entre os demais parasitóides, prova- velmente se deve a sua maior capacidade competitiva, como também ao fato de que alguns parasitóides têm a capacidade para detectar o hospedeiro já parasitado, descartando-o e buscando por outro mais adequado.

A incidência do predador Doru luteipes Scudder (Dermaptera: Forficulidae) foi observada a partir do sexto dia após a infestação, com uma média de 4,0 indivíduos/parcela (plantas com 21 dias após a emergência - DAE). Na coleta realizada 16 dias após a infestação (plantas com 31 DAE), o número coletado aumentou para 43 indivíduos, ou seja, média de 2,15/planta (Tabela 3). Sua presença a partir da terceira coleta de plantas de milho também está associada à redução do número de lagartas coletadas posteriormente. Portanto, juntamente com o parasitóide C. insularis, esse predador pode ser considerado um importante inimigo natural de $S$. frugiperda. A ocorrência desse predador foi evidenciada por Cruz \& Oliveira (1997), em estudos de vários anos, em Sete Lagoas, MG. Os autores salientaram que a presença de um casal de D. luteipes/ planta de milho poderia manter a população de S. frugiperda sob controle. Em plantios de dezembro a fevereiro, época semelhante ao do presente trabalho, Cruz \& Oliveira (1997) encontraram uma média de $43,6 \%$ de plantas contendo pelo menos um predador, sendo que, em época de pico, essa média chega até $62 \%$.

A ocorrência inicial de Orius sp. (Heteroptera: Anthocoridae) foi observada quando as plantas estavam com 25 dias, ou seja, aos 10 DAI, e as lagartas de $S$. frugiperda estavam com cerca de 11 dias (Tabela 3). Coccinellideos ocorreram inicialmente aos 12 DAI (plantas com 27 dias), quando as lagartas de $S$. frugiperda estavam com cerca de 13 dias.

Espécies de formigas (181 espécimes) e de aranhas (36), juntamente com outras, porém 
em menores proporções (outras espécies de Diptera, Hymenoptera, Coleoptera e Heteroptera), foram também coletadas durante a fase experimental (Tabela 3).

Todas as considerações anteriores confirmam a regulação natural da população da praga, principalmente, pelos inimigos naturais, no agroecossistema, e a presença desses deve ser levada em consideração antes de se adotar qualquer medida de controle para $S$. frugiperda na cultura do milho.

A diferenciação do período de coleta das plantas, após a infestação, propiciou avaliar a ocorrência dos diferentes inimigos naturais, desde a fase de ovo até os diferentes instares larvais da praga, sendo eles parasitóides e predadores de ovos e lagartas.

A compreensão e o estabelecimento dos fatores bióticos e ou abióticos que interferem na dinâmica de uma determinada população é de grande importância para o desenvolvimento de táticas de controle da espécie alvo, nesse caso, $S$. frugiperda, assim como o conhecimento dos inimigos naturais, associados à praga e à cultura do milho, para definir o método de controle mais eficaz, de forma a permitir a preservação dos agentes de controle no agroecossistema. A utilização de inseticidas, sem considerar a presença de inimigos naturais na área, pode incorrer no erro de se utilizar o produto sem ser necessário, como pode, também, ser o causador da sua necessidade, pela eliminação daqueles agentes de controle, quando o produto utilizado for de amplo espectro de ação.

\section{Agradecimentos}

Ao Conselho Nacional de Pesquisa (CNPq) o financiamento de parte desse trabalho.

Ao Dr. Ronaldo Toma (Museu de Zoologia da Universidade de São Paulo, USP), a identificação dos insetos da ordem Diptera.

TABELA 3. Número total de Arthropoda provenientes da avaliação das folhas destacadas individualmente das plantas de milho (20 plantas/parcelas), em coletas realizadas a cada dois dias após a infestação artificial com posturas da praga.

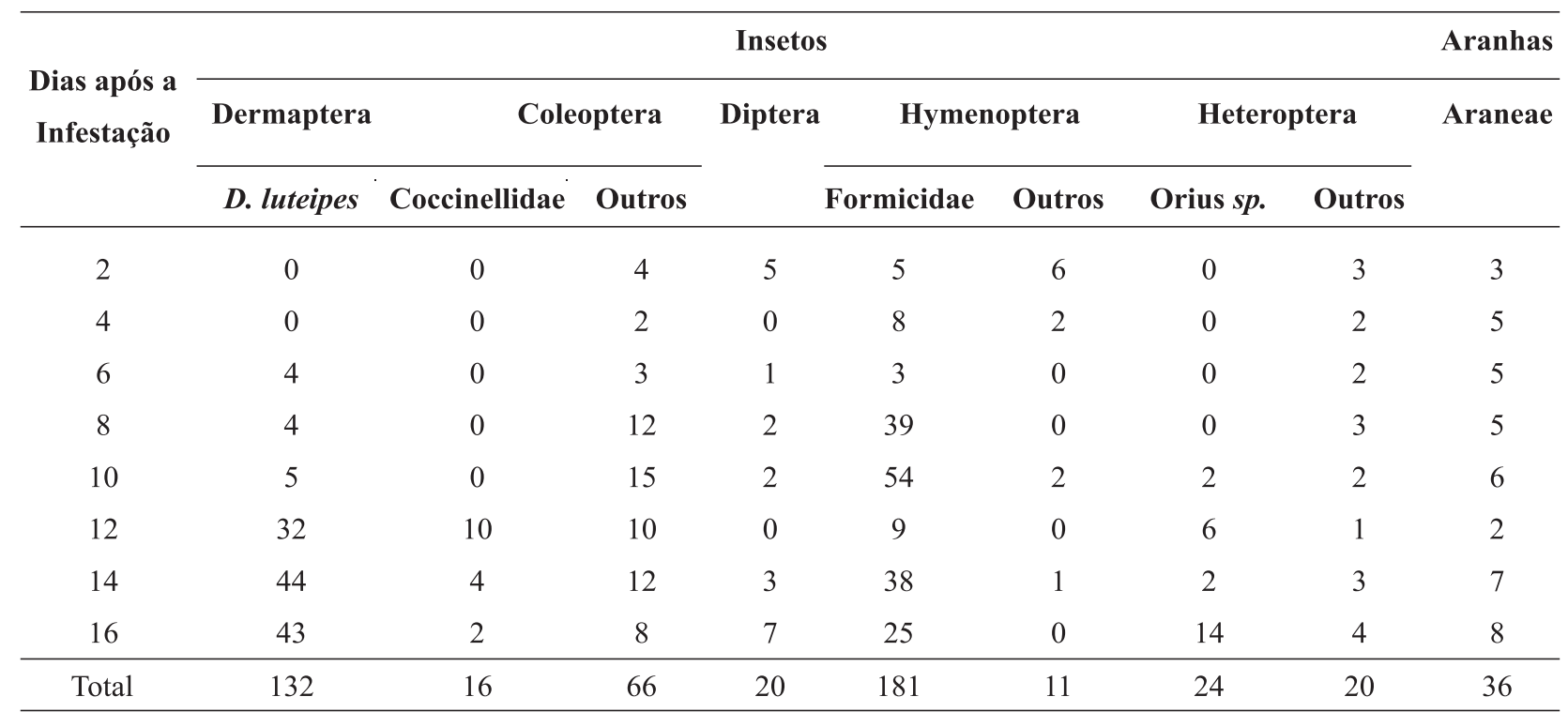




\section{Literatura Citada}

BESERRA, E.B.; DIAS, C.T.D.; PARRA, J.R.P. Distribution and natural parasitism of Spodoptera frugiperda (Lepidoptera: Noctuidae) eggs at different phenological stages of corn. Florida Entomologist, v.85, p.588-593, 2002.

CRUZ, I. A lagarta-do-cartucho na cultura do milho. Sete Lagoas: Embrapa-CNPMS, 45p. (Embrapa. CNPMS. Circular Técnica, 21). 1995.

CRUZ, I. Controle biológico em manejo integrado de pragas. p.543-570. In PARRA, J.R.P.; BOTELHO, P.S.M.; CORREA-FERREIRA, B.S.; BENTO, J.M.S. (Eds.), Controle biológico no Brasil: Parasitóides e predadores. São Paulo, MANOLE, 609p. 2002.

CRUZ, I.; TURPIN, F.T. Efeito da Spodoptera frugiperda em diferentes estágios de crescimento da cultura de milho. Pesquisa Agropecuária Brasileira, v.17, p.355-359, 1982.

CRUZ, I.; OLIVEIRA, A.C. Flutuação populacional do predador Doru luteipes Scudder em plantas de milho. Pesquisa Agropecuária Brasileira, v.32, p.363-368, 1997.

CRUZ, I.; OLIVEIRA, L. J.; OLIVEIRA, A.C.; VASCONCELOS, C.A. Efeito do nível de saturação de alumínio em solo ácido sobre os danos de Spodoptera frugiperda (J.E. Smith) em mi1ho. Anais da Sociedade Entomológica do Brasil, v.25, p.293-297, 1996.

CRUZ, I.; FIGUEIREDO, M.L.C.; GONÇALVES, E. P.; LIMA D.A.N.; DINIZ, E.E. Efeito da idade de lagartas de Spodoptera frugiperda (Smith) (Lepidoptera: Noctuidae) no desempenho do parasitóide, Campoletis flavicincta (Ashmead) (Hymenoptera: Ichneumonidae) e consumo foliar por lagartas parasitadas e não parasitadas. Anais da Sociedade Entomológica do Brasil, v.26, p.145-152, 1997.

CRUZ, I., FIGUEIREDO, M.L.C.; OLIVEIRA, A.C.; VASCONCELOS, C.A. Damage of Spodoptera frugiperda (Smith) in different maize genotypes cultivated in soil under three levels of aluminium saturation. International Journal of Pest Management, v.45, p.293-296, 1999.

FIGUEIREDO, M.L.C.; CRUZ, I.; DELLA LUCIA, T.M.C. Controle integrado de Spodoptera frugiperda (Smith \& Abbott) utilizando-se o parasitóide Telenomus remus Nixon. Pesquisa Agropecuária Brasileira, v.34, p.1975-1982, 1999.

FIGUEIREDO, M.L.C.; DELLA LUCIA, T.M.C.; CRUZ, I. Effect of Telenomus remus Nixon (Hymenoptera: Scelionidae) density on control of Spodoptera frugiperda (Smith) (Lepidoptera: Noctuidae) egg masses upon release in a maize field. Revista Brasileira de Milho e Sorgo, v.1, p.12-19, 2002.

GUIMARÃES, P.C.; DURÃES, F.O.M. Cultivo do milho. Germinação e Emergência. Sete Lagoas: Embrapa Milho e Sorgo, 2002. 9p. (Embrapa Milho e Sorgo. Comunicado Técnico, 39) Disponível em: http://www.cnpms.embrapa.br/ publicacoes/milho/ecofisiologia.htm. Acesso em: 11 abr., 2006.

HOBALLAH, M.E.; DEGEN, T.; BERGVINSON, D.; SAVIDAN, A.; TAMO, C.; TURLINGS, T.C.J. Occurrence and direct potential of parasitoids and predators of the fall armyworm (Lep.: Noctuidae) on maize in the subtropical lowlands of Mexico. Agricultural and Forest Entomology, v.6, p.83-88, 2004.

LUCCHINI, F.; ALMEIDA, A.A. Parasitas de Spodoptera frugiperda (Smith \& Abbot 1797) 
(Lepidoptera: Noctuidae) lagarta do cartucho do milho, encontrados em Ponta Grossa-PR. Anais da Sociedade Entomológica do Brasil, v.9, p.115-121, 1980.

MITCHELL, F.L.; FUXA. J.R. Distribution, abundance and sampling of fall armyworm (Lepidoptera: Noctuidae) in South-central Louisiana cornfields. Environmental Entomology, v.16, p.453-458, 1987.

MOLINA-OCHOA, J.; HAMM, J.J.; LEZAMAGUTIÉRREZ, R.; LÓPEZ-EDWARDS, M.; GONZÁLEZ-RAMÍREZ, M.; PESCADORRUBIO, A. A survey of fall armyworm (Lepidoptera: Noctuidae) parasitoids in the mexican states of Michoacán, Colima, Jalisco, and Tamaulipas. Florida Entomologist, v.84, p.31-36, 2001.

MOLINA-OCHOA, J.; CARPENTER, J.E.; LEZAMA-GUTIÉRREZ, R.; FOSTER, J. E.; GONZÁLEZ-RAMÍREZ, M.; ÁNGELSAHAGÚN, C.A.; FARÍAS-LARIOS, J. Natural distribution of hymenopteran parasitoids of Spodoptera frugiperda (Lepidoptera: Noctuidae) larvae in Mexico. Florida Entomologist, v.87, p.461-472. 2004.

MOLINARI, A.M.; AVALOS, S.D. Contribución al conocimiento de taquínidos (Diptera) parasitoides de defoliadores (Lepidoptera) del cultivo de la soja. Revista de la Sociedad Entomológica Argentina, v.5, p.131-136, 1997.

MURÚA, M.G.; MOLINA-OCHOA, J.; COVIELLA, C. Population dynamics of the fall armyworm, Spodoptera frugiperda (Lepidoptera: Noctuidae) and its parasitoids in northwestern
Argentina. Florida Entomologist, v.89, p.175182. 2006.

REIS, L.L.; OLIVEIRA, L.J.; CRUZ, I. Biologia e Potencial de Doru luteipes no controle de Spodoptera frugiperda. Pesquisa Agropecuária Brasileira, v.23, p.333-342, 1988.

REZENDE, M.A.A.; CRUZ, I.; DELLA LUCIA, T.M.C. Aspectos Biológicos do Parasitóide Chelonus insularis (Cresson) (Hymenoptera, Braconidae) criados em ovos de Spodoptera frugiperda (Smith) (Lepidoptera, Noctuidae). Revista Brasileira de Zoologia, v.12, p.779-784, 1995.

SANTOS, G.M.M.; MARQUES, O.M. Análise faunística de comunidades de formigas epígeas (Hymenoptera: Formicidae) em dois agroecossistemas em Cruz das Almas-Bahia. Insecta, v.5 p.1-17, 1996.

SILVA, F.M.A.; FOWLER, H.G.; LEMOS, R.N.S. Parasitismo em lagarta-do-cartucho, Spodoptera frugiperda (Smith), na região do Triângulo Mineiro, MG. Anais da Sociedade Entomológica do Brasil, v 26, p.235-241, 1997.

VALICENTE, F.H. Levantamento dos inimigos naturais de Spodoptera frugiperda em diferentes regiões do Estado de Minas Gerais. Anais da Sociedade Entomológica do Brasil, v.18, p.119130, 1989.

VALICENTE F.H.; BARRETO, M.R. Levantamento dos inimigos naturais da lagarta-do-cartucho do milho, Spodoptera frugiperda (J.E. Smith) (Lepidoptera: Noctuidae), na região de Cascavel, PR. Anais da Sociedade Entomológica do Brasil, v.28, p.333-337, 1999. 